|| ISSN(online): 2589-8698 || ISSN(print): 2589-868X || International Journal of Medical and Biomedical Studies

Available Online at www.ijmbs.info

NLM (National Library of Medicine ID: 101738825)

Index Copernicus Value 2018: 75.71

\title{
BLADDER INJURY IN CAESAREAN SECTION
}

\section{Dr. Narendra Vaghela}

Assistant Professor Dept. of Obstetric and Gynecology Govt. Medical College Surat, Gujarat.

Article Info: Received 17 May 2020; Accepted 17 June 2020

DOI: https://doi.org/10.32553/ijmbs.v4i6.1221

Corresponding author: Dr. Narendra Vaghela

Conflict of interest: No conflict of interest.

\section{Introduction}

If performed with appropriate medical indications, caesarean sections are potentially lifesaving procedures, but it can add risk to life of mother and baby if performed without appropriate indications. Maternal mortality and newborn mortality are not associated with caesarian section rates more than $10 \%$, as per WHO report at population level'. Women undergoing caesarean delivery had an increased risk of severe maternal morbidity compared with women undergoing vaginal delivery (odds ratio 2.0 (95\% confidence interval 1.6 to 2.5 ) for intrapartum caesarean and 2.3 (1.7 to 3.1) for elective caesarean) $)^{\mathrm{ii}}$. The median rate of caesarean delivery was $33 \%$ (quartile range 24-43), with the highest rates of caesarean delivery noted in private hospitals $(51 \%, 43-57)$. Rate of caesarean delivery was positively associated with postpartum antibiotic treatment and severe maternal morbidity and mortality iii. District Level Household Survey 3 (DLHS-3) reported that the caesarean section rate in India is $28.1 \%$ at private health institutions and $12 \%$ at public health facilities ${ }^{\text {iv }}$. Increase in rates of caesarean sections has been due to various reasons like fear of vaginal delivery, social norms and patients' preferences ${ }^{v}$, ${ }^{\prime}$.

Bladder injury commonly occurs during abdominal hysterectomy in gynecological surgery. A two- or threelayer closure with absorbable suture and Foley catheter bladder drainage can manage bladder and bladder filling with blue-colour saline again makes bladder injury diagnosis easier ${ }^{\text {vii }}$.

The anatomical proximity of the urinary bladder, close embryonic development and genital organs, are responsible for the urinary tract to injury during surgical procedures in the female pelvis ${ }^{\text {viii }}$.

The presence of gas filling up Foley bag or bloody urine visible in foley bag demonstrates the bladder injury during LCLS. Small needle injuries to bladder can be managed by catheter drainage followed by cystography. Bladder injuries from $5 \mathrm{~mm}$ to $10 \mathrm{~mm}$ trocar or surgical dissection usually requires suturing the injuries ${ }^{\text {ix }}$.

Signs and symptoms of unrecognized bladder injury can be drainage of surgical incision, vaginal leakage, increased output of surgical drains, urinary ascites and apparent oliguria ${ }^{\mathrm{x}}$.

Malignancy, exposure to radiation, inflammation, chronic infection and previous operations are risk factors of bladder injury during caesarean section ${ }^{\mathrm{xi}}$.

\section{Materials and Methods:}

This prospective study was carried out in GMC Surat Hospital in the department of OBGY in collaboration with surgery department. Written informed consent was taken from all participants. During the given study period 1012 LCLS were performed in Dept. of Obstetrics and Gynecology. Among 1312 LCLS, 33 cases were diagnosed with injury of bladder. Bladder injury was diagnosed according to its staging ${ }^{\text {xii }}$.

Grade1: Intramural hematoma, contusion or partial thickness laceration

Grade2: Intraperitoneal bladder wall laceration $2 \mathrm{~cm}$ or extra peritoneal wall laceration $2 \mathrm{~cm}$

Grade3: Extra peritoneal bladder wall laceration $>2 \mathrm{~cm}$ or intraperitoneal $2 \mathrm{~cm}$

Grade4: Intraperitoneal laceration of bladder wall $>2 \mathrm{~cm}$

Grade5: Either intraperitoneal or extra peritoneal bladder wall laceration involving bladder neck or trigone

Cystogram X-ray of bladder is performed after injecting contrast medium in case of suspected bladder injuries.

Treatment for extra peritoneal injuries without complicating factors is insertion of Foley catheter for 7 to 14 days. Injuries from grade 3 through grade 5 requires operative repairs generally. In most cases suprapubic placement of tube is not necessary. Mucosa is closed running fashion using vicryl 3.0 followed by vicryl 2.0 in case of injuries to dome, posterior bladder or ventral bladder. To ensure watertight closure, bladder is then irrigated. One-layer closure is performed with vicryl 2.0 in laparoscopic setting to close all layers of bladder. In cases with leakage identified or high risk of fistula formation a third layer can be used in lambert fashion. An additional layer using 2.0 vicryl can be added for more extensive injuries in lambert fashion.

The data of present study was entered in Microsoft Excel. Analysis of grading injury, repair of bladder and 
complications was done. Data was expressed in percentages.

\section{Results:}

In present study 33 cases were diagnosed with bladder injury among 1312 LCLS performed.

Table 1: Distribution of injuries among LCLS performed

\begin{tabular}{lcl}
\hline No bladder injury & Bladder injury & Total \\
\hline $1284(97.87 \%)$ & $28(2.13 \%)$ & $1312(100 \%)$ \\
\hline $2.13 \%$ of all cases & who underwent & caesarean section \\
suffered from bladder injuries. &
\end{tabular}

Table 2: Type of Gravida

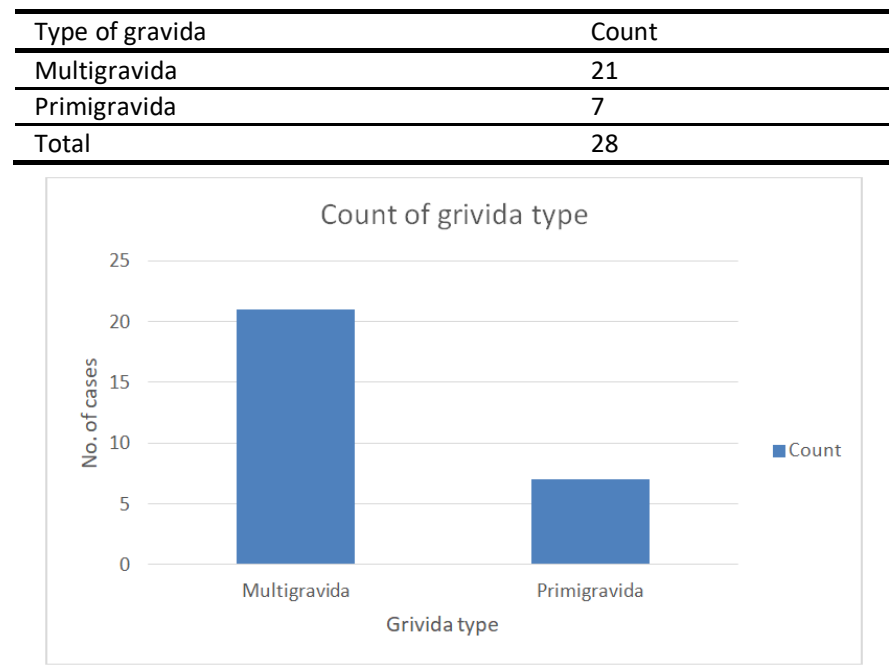

Figure1: Gravida type

Among 28 cases who suffered from bladder injury, 27 were multigravida and 7 cases were primi gravida type.

Table 3: Repairs of injuries

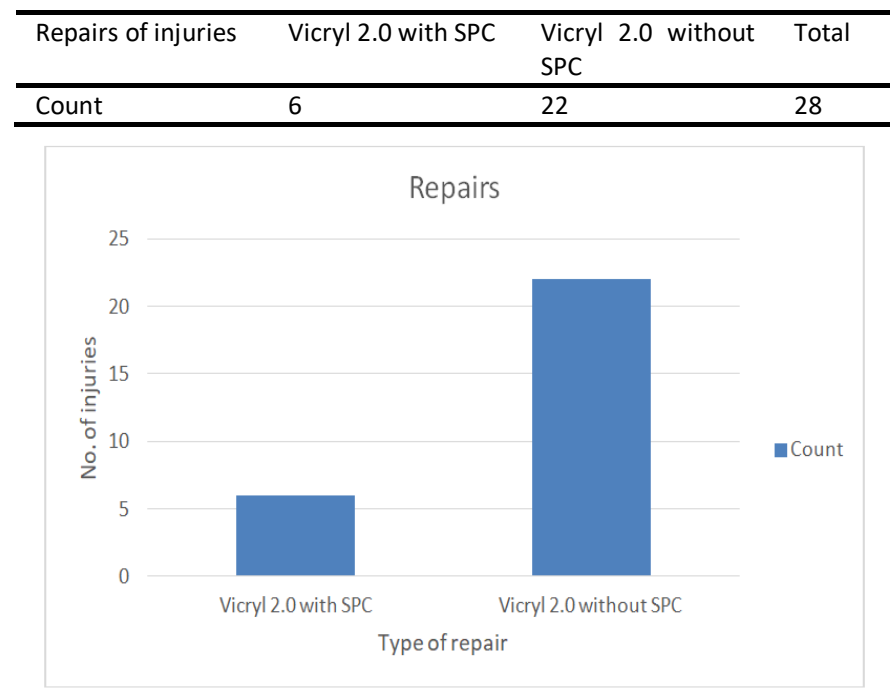

Figure 2: Repair type
Among 28 cases with bladder injuries, 6 injuries were repaired by insertion of SPC (suprapubic cystectomy) with 2 layers of vicryl 2.0 while 22 injuries were repaired without insertion of SPC. Patients were monitored for urine output, stiches site of wounds and vitals in postoprative period. Foley catheter and SPC catheter were removed in patients after 13 days of operation among 26 patients in whom no complication was found postoperatively and were discharged after 16 days of treatment. 2 surgical site compactions were treated with antibiotics and discharged after 25 days.

Discussion: Adhesions are because of abnormal wound healing in one of the most common obstetric surgeries of caesarean delivery $(C D)^{x i i i}$. Most important tool for surgeon is knowledge and understanding of anatomy. If fibrinolysis is suppressed i.e., by tissue ischemia and hypoxia, then fibrin deposits may persist and develop into adhesions. Other factors include residual blood, postoperative infection, inflammation and foreign bodies (e.g., sutures) ${ }^{\text {xiv }}$. The urinary tract is predisposed to injury during pelvic surgery due to close anatomic association of genital and urinary organ ${ }^{\mathrm{xv}}$.

In this study 1312 patients underwent caesarean section among which $28(2.13 \%)$ suffered from bladder injury. In those 28 cases of bladder injury, 7 cases were of primi gravida type and 21 of multigravida type of cases. 6 out of 28 cases were detected post operatively while 22 cases were detected intra-operatively during urinary leakage. Bladder injuries were repaired in 6 cases with insertion of SPC (suprapubic cystectomy) by vicryl 2.0 and 22 cases were repaired without insertion of SPC in two layers with vicryl 2.0. Intraoperative corrections provide better quality of life and less morbidity ${ }^{x i}$.

\section{Conclusion:}

$2.13 \%$ of bladder injuries were observed in our study. The morbidity and mortality in cases on which LCLS is performed can be reduced by early detection and prompt management of bladder injury.

\section{References:}

1. 'Souza J, Gulmezoglu A, Lumbiganon $P$, et al. Cesarean section without medical indications is associated with an increased risk of adverse short-term maternal outcomes: the 2004-2008 WHO global survey on maternal and perinatal health. BMC Med. 2010;8:71. doi: 10.1186/1741-7015-8-71.

2. ii Villar J, Carroli G, Zavaleta N, Donner A, Wojdyla D, Faundes A, Velazco A, Bataglia V, Langer A, Narváez A, Valladares E, Shah A, Campodónico L, Romero M, Reynoso S, de Pádua KS, Giordano D, Kublickas M, Acosta A, World Health Organization 2005 Global Survey on Maternal and Perinatal Health Research Group: Maternal and neonatal individual risks and benefits associated with caesarean delivery: multicentre prospective study. BMJ. 2007, 335: 1025-10.1136/bmj.39363.706956.55. 
3. iii Villar J, Valladares E, Wojdyla D, Zavaleta N, Carroli G, Velazco A, Shah A, Campodónico L, Bataglia V, Faundes A, Langer A, Narváez A, Donner A, Romero M, Reynoso S, de Pádua KS, Giordano D, Kublickas M, Acosta A, WHO 2005 Global Survey on Maternal and Perinatal Health Research Group: Caesarean delivery rates and pregnancy outcomes: the 2005 WHO global survey on maternal and perinatal health in Latin America. Lancet. 2006, 367: 18191829. 10.1016/S0140-6736(06)68704-7. Erratum in: Lancet 2006, 368:580

4. iv District level household \& facility survey (DLHS-3) [Internet]. Mumbai: International Institute for Population Sciences. Available from: http://rchiips.org/PRCH-3.html

5. Behague DP, Victora CG, Barros FC. Consumer demand for cesarean sections in Brazil: informed decision making, patient choice, or social inequality? A population based birth cohort study linking ethnographic and epidemiological methods. BMJ. 2002;324(7343):942. doi: 10.1136/bmj.324.7343.942.

6. vi Yoshioka-Maeda K, Ota E, Ganchimeg T, Kuroda M, Mori R. Cesarean section by maternal age group among singleton deliveries and primiparous Japanese women: a secondary analysis of the WHO global survey on maternal and perinatal health. BMC Pregnancy Childbirth. 2016;16(1):39. doi: 10.1186/s12884-0160830-2.

7. vii Ricardo Azziz, Geoffrey W. Cundiff, Robert E Bristow. Linde's Atlas of Gynecologic Surgery. Lippincott Williams and Wilkins. 64 ed.2014.

8. viii Raut V, Shrivastava A, Nandanwar S, Bhattacharya M. Urological injuries during obsteteic and gynecological surgical procedures. J Postgrad Med. 1991;37:21-3.

9. ${ }^{i x}$ Mann WJ, Arato M, Patsner B, Stone ML. Ureteral injuries in an obstetrics and gynecology training program: etiology and management. Obstet Gynecol. 1988;72:82-5.

10. 'Vaidya B, Chaudhari M, Parmar D, Chaudhari V, Daginawala T, Shah R. Bladder injuries during obstetrical and gynecological surgeries. Int Surg J 2017;4:2177-80.

11. ${ }^{\mathrm{xi}}$ Mann WJ, Arato M, Patsner B, Stone ML. Ureteral injuries in an obstetrics and gynecology training program: etiology and management. Obstet Gynecol. 1988;72:82-5.

12. ${ }^{x i i}$ Van Goor H. Consequences and complications of peritoneal adhesions. Colorectal Dis. 2007;9(s2):25- 34.

13. xiii Chegini $N$, Zhao $Y$, Kotseos $K$ et al. Differential expression of matrix metalloproteinase and tissue inhibitor of MMP in serosal tissue of intraperitoneal organs and adhesions. BJOG 109(9), 10411049 (2002).

14. ${ }^{x i v}$ Roset $\mathrm{E}$, Boulvain $\mathrm{M}$, Irion $\mathrm{O}$. Nonclosure of the peritoneum during caesarean section: long-term follow-up of a randomised controlled trial. Eur. J. Obstet. Gynecol. Reprod. Biol. 108(1), 40-44 (2003).

15. Raut V, Shrivastava A, Nandanwar S, Bhattacharya M. Urological injuries during obsteteic and gynecological surgical procedures. J Postgrad Med. 1991;37:21-3.

16. xvi Turk SK, Muneer L, Memon AS. Treatment of Gyneco-logical and obstetric ureteric injuries. J surg Pakistan Int. 1999;4:31-4. 